\title{
DNA Relatedness between Xenorhabdus spp. (Enterobacteriaceae), Symbiotic Bacteria of Entomopathogenic Nematodes, and a Proposal To Transfer Xenorhabdus luminescens to a New Genus, Photorhabdus gen. nov.
}

\author{
N. E. BOEMARE, ${ }^{1 *}$ R. J. AKHURST, ${ }^{2}$ AND R. G. MOURANT ${ }^{2}$ \\ Laboratoire de Pathologie Comparée, Institut National de la Recherche Agronomique et Centre National de \\ la Recherche Scientifique (URA 1184), Université Montpellier II, Sciences et Techniques du Languedoc, \\ 34095 Montpellier Cedex 05, France, ${ }^{1}$ and Division of Entomology, Commonwealth Scientific and \\ Industrial Research Organisation, Canberra, Australian Capital Territory 2601, Australia ${ }^{2}$
}

The levels of DNA relatedness for a broad sample of Xenorhabdus strains isolated from different species of entomopathogenic nematodes (Steinernematidae and Heterorhabditidae) and from different geographical sources were estimated by the hydroxyapatite method. The level of DNA-DNA relatedness for the two phases of each isolate tested was not significantly different from $100 \%$, demonstrating unequivocally that the phase variation demonstrated by all Xenorhabdus spp. is not due to contamination. The isolates of the described Xenorhabdus species coalesced into different DNA relatedness groups, confirming that Xenorhabdus nematophilus, Xenorhabdus bovienii, Xenorhabdus poinarii, and Xenorhabdus beddingii, defined on the basis of phenotypic differences, are valid species. The symbiont of Steinernema intermedia also coalesced with the $X$. bovienii isolates. This was the only symbiont of seven recently described and unamed Steinernema spp. (including Steinernema ritteri, Steinernema rara, and Steinernema anomali) that formed a group with any of the previously described Xenorhabdus species; new species descriptions are required to accommodate the other taxa, but too few isolates were available to allow satisfactory descriptions of them. The DNA relatedness data also showed that the bacteria currently classified as Xenorhabdus luminescens are significantly different from all other Xenorhabdus strains. These data strongly support indications from previous studies of phenotypic characteristics, cellular fatty acids, and DNA relatedness that $X$. luminescens should be classified as a separate genus. A new genus, Photorhabdus, with an amended description of the type species, Photorhabdus luminescens, is proposed.

The genus Xenorhabdus (Enterobacteriaceae) consists almost entirely of the bacterial symbionts of entomopathogenic nematodes belonging to the families Steinernematidae and Heterorhabditidae $(3,16,29)$. The bacterial symbionts are carried monoxenically in a special vesicle in the infective stage (L3 juveniles) of members of the Steinernematidae (8) and throughout the whole intestine of infective juveniles Heterorhabditidae (14), which provide protection and transport for their bacterial symbionts. The nematodes also provide protection for their symbionts against the host's immune response; during the early stage of the infection, LA and adult steinernematids produce an inhibitor of the insectinducible immune protein (17). Both nematodes and $\mathrm{Xe}$ norhabdus spp. are pathogenic for most insects when they are released into the hemolymph $(11,12,25)$. The bacterial symbionts also contribute to the symbiotic relationship by establishing and maintaining suitable conditions for nematode reproduction (24), providing nutrients and antimicrobial substances that inhibit the growth of a wide range of microorganisms $(2,10)$.

Phase variants of 21 strains of Xenorhabdus spp. from 14 nematode species isolated from various parts of the world were characterized biochemically and physiologically (9), and the data were analyzed by numerical taxonomy (6). On the basis of this evidence, the elevation of four subspecies of Xenorhabdus nematophilus to species status as $X$. nematophilus, Xenorhabdus bovienii, Xenorhabdus poinarii, and

\footnotetext{
* Corresponding author.
}

Xenorhabdus beddingii was proposed, and an emended description of the species Xenorhabdus luminescens was given.

The first genotypic study of Xenorhabdus spp. was an investigation of DNA relatedness (18). This demonstrated that there were substantial differences among $X$. nematophilus, $X$. luminescens, and a third group that clustered about what is now known as $X$. bovienii. Furthermore, the $X$. luminescens group was shown to contain four DNA relatedness groups. Farmer et al. (16) subsequently identified a fifth DNA group in $X$. luminescens when they examined some isolates taken from clinical specimens. None of the DNA relatedness groups was described as a separate species because too few strains had been studied.

There were some apparent anomalies in the distribution of $X$. luminescens into DNA relatedness groups. The American Type Culture Collection type strain of $X$. luminescens was assigned to a different DNA relatedness group than clones apparently isolated from the same nematode species. Moreover, two clones obtained from strain 18 were also assigned to different groups. Grimont et al. (18) suggested that dimorphism detected in Xenorhabdus spp. (1) might be explained by some strains being "mixed cultures containing two different luminous Xenorhabdus species."

We undertook a study of DNA-DNA relatedness in $X e$ norhabdus spp. to test the hypothesis of Grimont et al. (18) concerning dimorphism by using defined phase one and phase two cultures. We also sought to test and possibly extend the taxonomic scheme for Xenorhabdus spp. described by Akhurst and Boemare (6). 
TABLE 1. Sources of the Xenorhabdus strains used in this study

\begin{tabular}{|c|c|c|c|c|}
\hline \multicolumn{2}{|c|}{ Bacterium } & \multicolumn{2}{|c|}{ Nematode host } & \multirow{2}{*}{ Geographic source } \\
\hline Species & Strain & Species or family & Strain & \\
\hline$X$. luminescens & $\mathrm{Hb}^{\mathrm{T}}\left(=\operatorname{ATCC} 29999^{\mathrm{T}}\right)$ & $\begin{array}{r}\text { Heterorhabditis } \\
\text { bacteriophora }\end{array}$ & $\mathrm{Hb}$ & Australia \\
\hline$X$. luminescens & $\mathrm{C} 1$ & H. bacteriophora & $\mathrm{C} 1$ & United States \\
\hline$X$. luminescens & K81 & Heterorhabditis sp. & K81 & Guadeloupe \\
\hline$X$. luminescens & Meg & Heterorhabditis megidis & & United States \\
\hline$X$. nematophilus & $\operatorname{AN6}^{\mathrm{T}}\left(=\operatorname{ATCC} 19061^{\mathrm{T}}\right)$ & Steinernema carpocapsae & DD136 & United States \\
\hline$X$. nematophilus & A24 & S. carpocapsae & Agriotos & Russia \\
\hline$X$. nematophilus & $\mathrm{F} 1$ & S. carpocapsae & Plougastel & France \\
\hline$X$. poinarii & $\mathrm{G}^{\mathrm{T}}\left(=\mathrm{UQM} 2216^{\mathrm{T}}\right)$ & Steinernema glaseri & & United States \\
\hline$X$ poinarii & NC40 & S. glaseri & $\mathrm{NC40}$ & United States \\
\hline$X$. beddingii & $\mathrm{Q}^{\mathrm{T}}{ }^{\mathrm{T}}\left(=\mathrm{UQM} 2872^{\mathrm{T}}\right)$ & Steinernema sp. & Q58 & Australia \\
\hline$X$. bovienï & $\mathrm{T} 228^{\mathrm{T}}\left(=\mathrm{UQM} 2211^{\mathrm{T}}\right)$ & Steinernema feltiae & $\mathrm{T} 228$ & Australia \\
\hline$X$. bovienii & F3 & Steinernema affinis & F3 & France \\
\hline X. bovienii & SK2 & Steinernema kraussei & & Czechoslovakia \\
\hline Xenorhabdus sp. & $\mathrm{Si}$ & Steinernema intermedia & & United States \\
\hline Xenorhabdus sp. & Q1 & Steinernematidae & Q1 & Australia \\
\hline Xenorhabdus sp. & $\mathrm{SaV}$ & Steinernema anomali & Voronezh & Russia \\
\hline Xenorhabdus sp. & CBG & Steinernema sp. & CB2B & People's Republic of China \\
\hline Xenorhabdus sp. & W1 & Steinernema sp. & W1 & Australia \\
\hline Xenorhabdus sp. & K77 & Steinernema rara & K77 & Argentina \\
\hline Xenorhabdus sp. & K78 & Steinernema ritteri & K78 & Argentina \\
\hline
\end{tabular}

\section{MATERIALS AND METHODS}

Bacterial strains. The sources of bacterial isolates are listed in Table 1. For each strain we used two isolates (phase one and phase two cultures of the strain). Phase one bacteria were isolated directly from the infective-stage nematodes (stage L3), and phase two bacteria were isolated from in vitro cultures established with the nematodes and phase one symbionts. The phases of cultures are designated by the suffixes $/ 1$ and $/ 2$ (e.g., isolates $A N 6 / 1$ and AN6/2 are phase one and phase two cultures, respectively, of strain $\mathrm{AN}^{\mathrm{T}}[\mathrm{T}$ = type strain]), as previously described (9).

Bacterial DNA. DNA was extracted from all strains and phases and was purified by a modification of the Marmur method (20). The DNAs were fragmented by sonication until the average fragment size was about $0.5 \mathrm{kbp}$ as assessed by gel electrophoresis. Sonicated DNA preparations were dialyzed against $0.28 \mathrm{M}$ phosphate buffer $(\mathrm{pH} 7.0)$ and stored at $4^{\circ} \mathrm{C}$ with some drops of chloroform.

Labelling DNA. DNA was labelled with ${ }^{32} \mathrm{P}$ by nick translation by using the protocol of Maniatis et al. (23). Labelled DNA was separated from free radioactive nucleotides by overnight dialysis against $0.1 \times$ TE buffer.

DNA hybridizations. Hybridizations were carried out in Eppendorf tubes containing $30 \mu \mathrm{g}$ of unlabelled test DNA and $0.01 \mu \mathrm{g}$ of labelled reference DNA in $300 \mu \mathrm{l}$ of $0.28 \mathrm{M}$ phosphate buffer. The mixture was heated $\left(100^{\circ} \mathrm{C}, 10 \mathrm{~min}\right)$, placed in ice for a few minutes, and then incubated overnight at $60^{\circ} \mathrm{C}$. The molarity of the phosphate buffer was adjusted to $0.14 \mathrm{M}$ immediately before $200-\mu$ l aliquots of each sample were loaded onto a hydroxyapatite chromatography column.

For each experiment, two control hybridizations were run in duplicate. The first control, containing only labelled DNA, allowed estimation of binding of the reference DNA back to itself, providing a baseline. In the second control the unlabelled DNA was taken from the same DNA sample as the reference DNA (i.e., 100\% relatedness).

Hybridizations between phase one and phase two cultures of each strain were carried out. The type strains of the Xenorhabdus species $\left(\mathrm{AN}^{\mathrm{T}}, \mathrm{T} 228^{\mathrm{T}}, \mathrm{G} 6^{\mathrm{T}}, \mathrm{Q} 58^{\mathrm{T}}\right.$, and $\mathrm{Hb}^{\mathrm{T}}$ ) and symbionts isolated from nematode species other than the hosts of the type strains (K77, SaV, Si, K78, CBG, Q1, $\mathrm{W} 1, \mathrm{~K} 81, \mathrm{C} 1$, and $\mathrm{Meg}$ ) were compared with each other. Other strains of $X$. nematophilus, $X$. poinarii, and $X$. bovienii were hybridized to some members of the first set so that within-group and between-group levels of relatedness could be assessed more thoroughly.

For pairwise comparisons, reciprocal hybridizations were carried out (i.e., first one strain and then the other was used as the labelled strain). Although most pairwise comparisons were replicated, it was not logistically feasible to do multiple replications of each pairwise comparison. However, for pairwise comparisons that were critical (e.g., type strains) or for pairwise comparisons for which values that varied significantly from expectations based on phenotypic and nematode host data were obtained, multiple replications (up to eight) were performed to ensure a high level of precision.

Estimation of DNA relatedness. The microcolumn method of Lachance (22) was used to separate single-stranded DNA and double-stranded (DS) DNA at $60^{\circ} \mathrm{C}$. Single-stranded DNA was eluted at a low molarity $(0.14 \mathrm{M}$ phosphate buffer $)$, and then the DS DNA was eluted in $0.48 \mathrm{M}$ phosphate buffer. The two samples eluted from the microcolumns were each mixed with $6 \mathrm{ml}$ of aqueous scintillation fluid and counted with a Beckman model LS 2800 scintillation counter.

The proportion of DS DNA calculated from these measurements was then used to estimate the relative binding ratio (RBR) or level of relatedness between the reference strain and the test strain as follows: $\mathrm{RBR}=100 \times[(\mathrm{PT}-$ PC1)/(PC2 - PC1)], where RBR is the RBR for test isolate T and the reference isolate, expressed as a percentage; PT is the proportion of DS DNA for the test-reference pair; $\mathrm{PC1}$ is the proportion of DS DNA for the $100 \%$ relatedness control (mean of two replicates); and PC2 is the proportion of DS DNA for the baseline control (mean of two replicates).

Statistical analysis. Data were analyzed by Student's $t$ test (27). The variation from $100 \%$ for the RBRs for each phase one-phase two comparison was tested, and the RBRs for 
TABLE 2. Levels of DNA relatedness for Xenorhabdus strains for which all pairwise comparisons were made

\begin{tabular}{|c|c|c|c|c|c|c|c|c|c|c|c|c|c|c|c|}
\hline \multicolumn{2}{|c|}{ Bacterium } & \multicolumn{14}{|c|}{ RBR (\%) with strain ${ }^{a}:$} \\
\hline Species & Strain & $\mathrm{Hb}^{\mathrm{T}}$ & K81 & $\mathrm{Cl}$ & Meg & $\mathrm{AN}^{\mathrm{T}}$ & $\mathrm{G} 6^{\mathrm{T}}$ & $\mathrm{T} 228^{\mathrm{T}}$ & $\mathrm{Si}$ & Q58 ${ }^{\mathrm{T}}$ & K 77 & $\mathrm{SaV}$ & Q1 & CBG & W1 \\
\hline$X$. luminescens & K81 & 63 & & & & & & & & & & & & & \\
\hline$X$. luminescens & $\mathrm{C} 1$ & 32 & 54 & & & & & & & & & & & & \\
\hline$X$. luminescens & Meg & 32 & 53 & 86 & & & & & & & & & & & \\
\hline$X$. nematophilus & $\mathrm{AN}^{\mathrm{T}}$ & 11 & 14 & 14 & 16 & & & & & & & & & & \\
\hline$X$. poinarii & $G 6^{\mathrm{T}}$ & 11 & 13 & 12 & 6 & 19 & & & & & & & & & \\
\hline$X$. bovienii & $\mathrm{T} 228^{\mathrm{T}}$ & 5 & 13 & 7 & 10 & 19 & 28 & & & & & & & & \\
\hline Xenorhabdus sp. & $\mathrm{Si}$ & 7 & 10 & 7 & 6 & 32 & 23 & 64 & & & & & & & \\
\hline$X$. beddingii & $\mathrm{Q}^{\mathrm{T}}$ & 8 & 6 & 15 & 14 & 31 & 25 & 27 & 17 & & & & & & \\
\hline Xenorhabdus sp. & K77 & 12 & 12 & 9 & 11 & 33 & 23 & 17 & 29 & 25 & & & & & \\
\hline Xenorhabdus sp. & SaV & 11 & 10 & 13 & 14 & 29 & 23 & 22 & 27 & 32 & 32 & & & & \\
\hline Xenorhabdus sp. & Q1 & 6 & 19 & 13 & 23 & 30 & 17 & 28 & 33 & 37 & 24 & 43 & & & \\
\hline Xenorhabdus sp. & CBG & 10 & 15 & 18 & 14 & 36 & 31 & 25 & 20 & 35 & 16 & 48 & 38 & & \\
\hline Xenorhabdus sp. & W1 & 9 & 14 & 13 & 10 & 30 & 28 & 17 & 18 & 29 & 16 & 43 & 48 & 44 & \\
\hline Xenorhabdus sp. & K78 & 13 & 20 & 16 & 20 & 38 & 23 & 26 & 28 & 25 & 27 & 24 & 31 & 31 & 19 \\
\hline
\end{tabular}

${ }^{a}$ For each pair, the mean of RBR data for phase one and phase two cultures and for reciprocal hybridizations.

reciprocal hybridizations were compared. The same test was used to assess whether a particular RBR was significantly different from a particular RBR range $(>60,>20$, or $<20 \%)$.

Phenotypic characterization. A total of $29 \mathrm{X}$. luminescens isolates were examined for the main phenotypic characteristics that distinguish $X$. luminescens from the other $X e$ norhabdus spp. (6) by using the methods of Boemare and Akhurst (9).

\section{RESULTS}

DNA relatedness. There was no significant difference $(P<$ $0.05)$ from $100 \%$ for the relatedness of phase one and phase two cultures for any of the 20 strains examined. There was also no significant difference $(P<0.05)$ in RBR between the reciprocal hybridization data for any strain. Consequently, the data for phase one and phase two cultures of each strain and for the reciprocal hybridizations of each pair were combined for the calculation of the mean RBR for each pair of strains. The mean RBRs calculated in this way (Tables 2 and 3) were used to assess the relationships among the 20 strains examined. The data matrix is incomplete because all possible pairwise comparisons were not made. An interpretation of the data is presented as a complete matrix in Fig. 1.

The mean RBRs for all pairs of strains generally fell into three classes: $>60,20$ to 60 , and $<20 \%$ (Tables 2 and 3 ). The values for reassociation between strains belonging to the same phenotypic species (e.g., $X$. bovienii $\mathrm{T} 228^{\mathrm{T}}, \mathrm{F} 3$, and SK2) were significantly more than $60 \%(P<0.05)$. The level of hybridization between an $X$. luminescens strain and a non- $X$. luminescens strain was never significantly more than 20\% $(P<0.05)$. The levels of relatedness between most non- $X$. luminescens strains were not significantly more than $20 \%(P<0.05)$.

Rarely was the level of hybridization between strains belonging to different species in the range from 38 to $60 \%$. Undescribed strains $\mathrm{SaV}, \mathrm{Q} 1, \mathrm{~W} 1$, and CBG seem to form an unusual group because the pairwise relatedness levels were $43 \pm 5 \%$. Si was the only strain not previously classified (Tables 2 and 3) that exhibited more than $60 \%$ relatedness with a named species; its levels of relatedness with the three strains of $X$. bovienii were not significantly more than $60 \%(P$ $<0.05)$.

Phenotypic results. Phenotypic characterization of $X$. luminescens isolates from a range of Heterorhabditis spp. and from a range of geographical locations showed that some characteristics for which $X$. luminescens was previously described as positive (6) should now be considered variable characteristics. Only 6 of the 29 isolates produced indolpyruvic acid from tryptophan, 18 hydrolyzed esculin, and gluconate and inositol were assimilated by only 24 and 18 isolates, respectively. Lipolysis of Tween 85 occurred in 26 of the 29 isolates.

The phenotypic characteristics that are most useful for distinguishing $X$. luminescens from other Xenorhabdus species are presented in Table 4.

\section{DISCUSSION}

This DNA relatedness study demonstrates unequivocally that phase variation in the genus Xenorhabdus $(1,9)$ is a real phenomenon and not merely an artifact due to contamination, as has been suggested previously (18). The level of DNA relatedness between the two phases of any strain was

TABLE 3. Levels of DNA relatedness for Xenorhabdus strains for which supplementary comparisons were made

\begin{tabular}{|c|c|c|c|c|c|c|c|c|c|}
\hline \multicolumn{2}{|c|}{ Bacterium } & \multicolumn{8}{|c|}{ RBR $(\%)$ with strain ${ }^{a}:$} \\
\hline Species & Strain & $\overline{\mathrm{Hb}^{\mathrm{T}}}$ & $\mathrm{AN6}^{\mathrm{T}}$ & $\mathrm{G6}^{\mathrm{T}}$ & $\mathrm{T}^{2} 28^{\mathrm{T}}$ & $\mathrm{Si}$ & ${\mathrm{Q} 58^{\mathrm{T}}}^{\mathrm{T}}$ & $\mathbf{K} 77$ & $\mathrm{SaV}$ \\
\hline$X$. nematophilus & A24 & 10 & 75 & 23 & 16 & $\mathrm{ND}^{b}$ & 19 & 26 & 32 \\
\hline$X$. nematophilus & F1 & 4 & 63 & 20 & 24 & 24 & 24 & 27 & 33 \\
\hline$X$. bovienii & F3 & 9 & 27 & 28 & 75 & 68 & 33 & 27 & 20 \\
\hline$X$. bovienii & SK2 & 9 & 32 & 14 & 75 & 57 & 27 & ND & 22 \\
\hline$X$. poinarii & $\mathrm{NC40}$ & 11 & 26 & 71 & 19 & 29 & 24 & ND & 25 \\
\hline
\end{tabular}

${ }^{a}$ For each pair, the mean of RBR data for phase one and phase two cultures and for reciprocal hybridizations.

${ }^{b} \mathrm{ND}$, not done. 


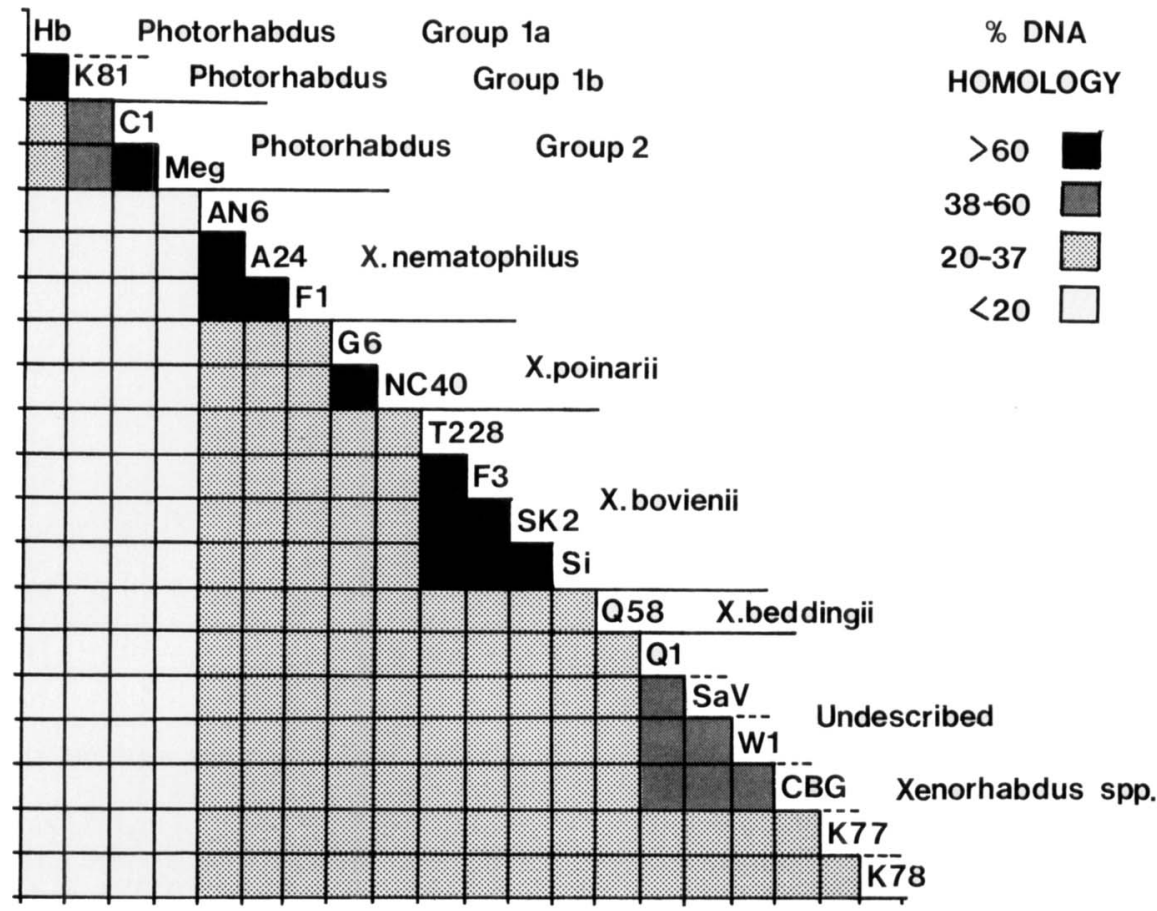

FIG. 1. Interpretation of the DNA relatedness data showing the levels of relatedness of 20 strains of bacterial symbionts of entomopathogenic nematodes.

higher than the level of DNA relatedness between two strains belonging to any one species. The experimental error inherent in the estimation of levels of DNA relatedness means that it is impossible to be certain that two samples of DNA are completely homologous. However, since the levels of DNA relatedness of phase one and phase two cultures

TABLE 4. Characteristics distinguishing between $X$. luminescens and Xenorhabdus spp. associated with members of the family Steinernematidae

\begin{tabular}{lcc}
\hline \multicolumn{1}{c}{ Characteristic } & $\begin{array}{c}\text { Xenorhabdus species associated } \\
\text { with members of the } \\
\text { Steinernematidae }\end{array}$ & $\begin{array}{c}\boldsymbol{X} . \\
\text { luminescens }\end{array}$ \\
\hline Bioluminescence & $-^{a}$ & + \\
Catalase & - & + \\
Insect pathogenicity $^{b}$ & $\mathrm{~d}$ & + \\
Lecithinase $^{c}$ & $\mathrm{~d}$ & + \\
Urease $_{\text {Indole }}$ & - & $\mathrm{d}$ \\
Utilization of: & - & $\mathrm{d}$ \\
Arbutin & & $\mathrm{d}$ \\
$N$-Caproate & - & - \\
Diaminobutane & $\mathrm{d}$ & - \\
DL-Lactate & $\mathrm{d}$ & - \\
Ribose & $\mathrm{d}$ & + \\
Trehalose & $\mathrm{d}$ & $\mathrm{d}$ \\
Tyrosine & + & + \\
\hline
\end{tabular}

$a+,>90 \%$ of the strains are positive;,- 0 to $9.9 \%$ of the strains are positive; $d, 10$ to $89.9 \%$ of the strains are positive.

$b$ The $50 \%$ lethal dose is less than 1,000 cells when the organisms are injected into the hemocoel of insects.

c This is a phase-related characteristic (6) and is normally detected only in phase one; it was detected in phase one of 24 of 25 strains for which both phases were available. No phase one cultures could be obtained for five clinical strains of $X$. luminescens (16) included in this study; all of these strains were negative for lecithinase activity. were not significantly different from $100 \%$, in each strain the phases must share a common genome, or at least very similar genomes.

The validity of the species $X$. nematophilus, $X$. poinarii, $X$. bovienii, and $X$. beddingii, which were described on the basis of phenotypic characteristics (6), was confirmed. There was a strong clustering of the data, with 98 of 105 pairs of strains having levels of DNA relatedness of either $>60$ or $<40 \%$. Those strains that had previously been characterized $(3,9)$ as $X$. nematophilus (AN6 ${ }^{\mathrm{T}}, \mathrm{A} 24$, and $\mathrm{F} 1$ ), $X$. poinarii $\left(\mathrm{G}^{\mathrm{T}}\right.$ and $\left.\mathrm{NC} 40\right)$, or $X$. bovienii (T228 ${ }^{\mathrm{T}}, \mathrm{F} 3$, and SK2) formed distinct groups with more than $60 \%$ internal relatedness and with less than $40 \%$ relatedness to any other strain (Fig. 1). The one strain included in this study that had previously been characterized as $X$. beddingii exhibited less than $37 \%$ relatedness with all other strains and clearly represents a distinct taxon. These data are similar to previously published data (18), except for the relatedness of $X$. nematophilus and $X$. poinarii. Suzuki et al. (28) found that strain G21 of $X$. poinarii exhibited a high degree of relatedness (66 to 106\%) to five strains of $X$. nematophilus, whereas in the study reported here we found that the type strains of these species exhibited only $19 \%$ relatedness (Table 2 ). This latter value was corroborated by the values for relatedness between the type strains and other members of these species (Table 3). The only phenotypic data provided for the strain used by Suzuki et al. (28) was fatty acid composition, which, according to the data of Janse and Smits (21), is unsuitable for resolving differences between $X$. nematophilus and $X$. poinarii. It seems probable that strain G21 was misidentified.

Of the strains that had not been previously identified as one of the named species (with the exception of the $X$. luminescens strains), only $\mathrm{Si}$ could be assigned to a previously defined group. This strain clearly belongs to the $X$. bovienii DNA relatedness group, which contains the sym- 
bionts of four nematode species, Steinernema feltiae (= Steinernema bibionis), Steinernema kraussei, Steinernema affinis, and Steinernema intermedia.

Six strains could not be assigned to any of the DNA relatedness groups. Strains K77 and K78 did not exhibit more than $38 \%$ relatedness with any other strain and exhibited only $27 \%$ relatedness between themselves. These strains probably represent new species. The levels of DNA relatedness for the remaining undescribed strains, SaV, Q1, W1, and CBG, range between 38 and $48 \%$, suggesting that each of these four strains represents a distinct species. These species are more closely related to one another than any other Xenorhabdus species are. However, since each of these six putative species is represented by only one isolate, no satisfactory species definitions could be made.

The $X$. luminescens strains clearly form a DNA relatedness group that is distinct from all of the other Xenorhabdus strains. These DNA reassociation data strongly support other DNA relatedness data (18), phenotypic data $(6,9)$, and chemotaxonomic data (28) in showing that $X$. luminescens is significantly different from the other Xenorhabdus spp. In the data presented here the four $X$. luminescens strains exhibited less than $20 \%$ homology to any other Xenorhabdus strain, whereas the levels of relatedness between the other Xenorhabdus strains were generally more than $20 \%$ and up to $48 \%$. Similarly, Suzuki et al. (28) found that the levels of DNA relatedness between $X$. nematophilus and $X$. bovienii ranged between 31 and $46 \%$, but the levels of DNA relatedness between these species and $X$. luminescens were only 7 to $27 \%$. Grimont et al. (18) found little difference between the levels of DNA relatedness of $X$. nematophilus and $X$. luminescens and the levels of relatedness between either of these two species and members of 73 DNA relatedness groups belonging to the family Enterobacteriaceae. The DNA relatedness data are also supported by $16 \mathrm{~S}$ RNA oligonucleotide cataloging data $(13,26)$. The dendrogram of $S_{\mathrm{AB}}$ data may present unreliable estimates of relationships because of group size dependency in the sorting strategy. Examination of the basic data shows that $X$. nematophilus was as dissimilar from $X$. luminescens as it was from Escherichia coli $\left(S_{\mathrm{AB}}, 0.70\right)(13,26)$.

$X$. luminescens strains are also well distinguished phenotypically from all other Xenorhabdus spp. (Table 4). Among the differentiating characteristics are bioluminescence and catalase activity, which are both physiologically very significant. $X$. luminescens is the only terrestrial bioluminescent bacterium, and the absence of catalase activity in the other Xenorhabdus spp. is very unusual for the Enterobacteriaceae. Since all Xenorhabdus strains occupy very similar environmental niches, major physiological differences are particularly significant taxonomic indicators. The differences between the two groups is also demonstrated by their interactions with nematodes. $X$. luminescens isolates do not support culture of any Steinernema species in vitro (4) but may support culture of nonhost Heterorhabditis spp. $(7,19)$. Similarly, the other Xenorhabdus spp. do not support culture of Heterorhabditis species (4a) but may support culture of nonhost Steinernema spp. (4). Further evidence of significant differences between $X$. luminescens and other $X e$ norhabdus spp. is provided by chemotaxonomic studies. Independent studies of $X$. nematophilus, $X$. bovienii, $X$. poinarii, and $X$. luminescens demonstrated significant qualitative and quantitative differences in the cellular fatty acid compositions of $X$. luminescens and the other Xenorhabdus species $(21,28)$. Phenotypically and genotypically $X$. lumi- nescens is so distinct from other Xenorhabdus spp. that it should be assigned to a separate genus.

There are evidently several subgroups within $X$. luminescens. Grimont et al. (18) recognized four DNA relatedness groups. A fifth relatedness group was identified when $X$. luminescens was isolated from human clinical specimens not associated with entomopathogenic nematodes (16). The four $X$. luminescens isolates used in the study described here form at least two groups: strains $\mathrm{C} 1$ and $\mathrm{Meg}$, with $86 \%$ relatedness, and strains $\mathrm{Hb}^{\mathrm{T}}$ and $\mathrm{K} 81$, with $63 \%$ relatedness. The lower level of relatedness of the latter group and the difference in the levels of relatedness of $\mathrm{Hb}^{\mathrm{T}}$ with $\mathrm{Cl}$ and Meg (32 and 32\%) and of K81 with these strains (54 and 53\%) indicate that $\mathrm{Hb}^{\mathrm{T}}$ and $\mathrm{K} 81$ might represent two groups. Like the studies of Grimont et al. (18) and Farmer et al. (16), this study did not include a sufficient variety of $X$. luminescens isolates to allow satisfactory definition of the subgroups. A study which includes $X$. luminescens isolates from a broad range of host and geographic sources is required. Consequently, the creation of a new genus to accommodate $X$. luminescens is proposed without the resolution of the taxonomic status of the subgroups. The description below is based on the data of Akhurst (3), Farmer (15), Grimont et al. (18), Akhurst and Boemare (5), Boemare and Akhurst (9), and Farmer et al. (16) and the phenotypic data obtained in this study.

Description of Photorhabdus Boemare, Akhurst, and Mourant gen. nov. Photorhabdus (Pho.to.rhab'dus. Gr. n. photo, light; Gr. fem. n. rhabdus, rod; M.L. n. Photorhabdus, bioluminescent rod-shaped bacterium). Gram-negative, asporogenous rods. Cell size is highly variable within and between cultures, ranging from 2 by 0.5 to 10 by $2 \mu \mathrm{m}$, with occasional filaments up to $30 \mu \mathrm{m}$ long; spheroplasts occur in the last stage of exponential growth. Motile and peritrichous. Most strains produced red-, pink-, or yellow-pigmented colonies, especially on rich media (tryptic soya agar, yolk nutritive agar). Facultatively anaerobic; metabolism respiratory and fermentative. Bioluminescent, usually detectable by a dark-adapted eye; bioluminescence intensity varies within and between isolates and may be detectable only with a photometer or scintillation counter in some isolates. One nonluminescent isolate is known. Catalase positive. Does not reduce nitrate. Negative for oxidase, $o$-nitrophenyl- $\beta$-Dgalactopyranoside, Voges-Proskauer, arginine dihydrolase, and lysine and ornithine decarboxylase tests. Proteolytic for gelatin. Lipolytic activity on Tween 20; many strains are lipolytic for Tween 40, Tween 60, Tween 80 and/or Tween 85. Acid is produced from glucose without gas; acid is produced from very few other carbohydrates. Acid is produced from fructose, mannose, and $N$-acetylglucosamine; acid production from glycerol, ribose, and maltose is variable. Succinate, fumarate, L-tyrosine, L-glutamate, and glucosamine are utilized as sole carbon and energy sources. The optimum temperature is usually ca. $25^{\circ} \mathrm{C}$; some strains do not grow at $37^{\circ} \mathrm{C}$. Pathogenic for insects; the $50 \%$ lethal dose is less than 100 cells when the organisms are injected into Galleria mellonella hemocoel. The $\mathrm{G}+\mathrm{C}$ content of the DNA is 43 to $44 \mathrm{~mol} \%$. The natural habitat for most strains is the intestinal lumen of entomopathogenic nematodes belonging to the family Heterorhabditidae and insects infected by these nematodes; one DNA relatedness group is associated with human clinical specimens.

Within an isolate colony morphology may be highly variable. Two extreme types are characterized as phases one and two. Phase one is found in the infective stage of the nematode host; phase two is known only from in vitro 
culture and clinical specimens. Phase one cultures produce highly mucoid colonies and absorb dye, forming red colonies from MacConkey agar; they also adsorb other dyes, such as bromothymol blue and Congo red. A large proportion of cells contain proteinic inclusion bodies. Phase one cultures produce agar-diffusible antimicrobial compounds and lecithinase. Phase one is very much more bioluminescent and more lipolytic than phase two. In pigmented strains, phase one is differently pigmented than phase two. Phase two colonies are not mucoid and do not absorb dye; very weak antimicrobial and lecithinase activities may be detected. The change from phase one to phase two usually occurs during the stationary period of in vitro cultures; change from phase two to phase one has not been demonstrated. Several intermediate colony forms, possessing at least some phase one properties, have been described.

The type species is Photorhabdus luminescens (Poinar and Thomas 1979) Boemare, Akhurst, and Mourant comb. nov.

Emended description of Photorhabdus luminescens (Poinar and Thomas 1979) Boemare, Akhurst, and Mourant. Large rods ( 2 by 0.5 to 6 by $1.4 \mu \mathrm{m}$ ). Bioluminescence is more than 100 -fold greater in phase one than in phase two. Indole reaction positive or weak in at least one phase for most strains. Citrate is utilized as a sole carbon and energy source. Acid is produced from inositol and maltose by most strains. Inclusion bodies occur in phase one cell protoplasm and are poorly produced in phase two cultures. The $\mathrm{G}+\mathrm{C}$ content of the DNA is 43.0 to $44.0 \mathrm{~mol} \%$. The natural habitat is the intestinal lumen of entomogenous nematodes such as Heterorhabditis bacteriophora and insects infected by these nematodes. Type strain $\mathrm{Hb}$ has been deposited in the American Type Culture Collection under accession number ATCC 29999.

\section{ACKNOWLEDGMENTS}

We thank R. Morton, CSIRO Biometric Unit, for advice on statistical analyses and J. Luciani for technical assistance.

We also thank the Institut National de la Recherche Agronomique and CSIRO for financial support enabling, under an agreement, exchanges between France and Australia.

\section{REFERENCES}

1. Akhurst, R. J. 1980. Morphological and functional dimorphism in Xenorhabdus spp., bacteria symbiotically associated with the insect pathogenic nematodes Neoaplectana and Heterorhabditis. J. Gen. Microbiol. 121:303-309.

2. Akhurst, R. J. 1982. Antibiotic activity of Xenorhabdus spp., bacteria symbiotically associated with insect pathogenic nematodes of the families Heterorhabditidae and Steinernematidae. J. Gen. Microbiol. 128:3061-3065.

3. Akhurst, R. J. 1983. Taxonomic study of Xenorhabdus, a genus of bacteria symbiotically associated with insect-pathogenic nematodes. Int. J. Syst. Bacteriol. 33:38-45.

4. Akhurst, R. J. 1983. Neoaplectana species: specificity of association with bacteria of the genus Xenorhabdus. Exp. Parasitol. 55:258-263.

4a.Akhurst, R. J. Unpublished data.

5. Akhurst, R. J., and N. E. Boemare. 1986. A non-luminescent strain of Xenorhabdus luminescens (Enterobacteriaceae). J. Gen. Microbiol. 132:1917-1922.

6. Akhurst, R. J., and N. E. Boemare. 1988. A numerical taxonomic study of the genus Xenorhabdus (Enterobacteriaceae) and proposed elevation of the subspecies of $X$. nematophilus to species. J. Gen. Microbiol. 134:751-761.

7. Akhurst, R. J., and N. E. Boemare. 1990. Biology and taxonomy of Xenorhabdus, p. 75-90. In R. R. Gaugler and H. K. Kaya (ed.), Entomopathogenic nematodes in biological control. CRC Press, Boca Raton, Fla.

8. Bird, A. F., and R. J. Akhurst. 1983. The nature of the intestinal vesicle in nematodes of the family Steinernematidae. Int. J. Parasitol. 13:599-606.

9. Boemare, N. E., and R. J. Akhurst. 1988. Biochemical and physiological characterization of colony form variants in $\mathrm{Xe}$ norhabdus spp. (Enterobacteriaceae). J. Gen. Microbiol. 134: $1835-1845$.

10. Boemare, N. E., M.-H. Boyer-Giglio, J.-O. Thaler, R. J. Akhurst, and M. Brehélin. 1992. Lysogeny and bacteriocinogeny in Xenorhabdus spp., bacteria associated with entomopathogenic nematodes. Appl. Environ. Microbiol. 58:30323037.

11. Boemare, N. E., C. Laumond, and J. Luciani. 1982. Mise en évidence de la toxicogénèse provoquée par le nématode entomophage Neoaplectana carpocapsae Weiser chez l'insecte Galleria mellonella. C. R. Acad. Sci. Ser. III 295:543-546.

12. Burman, M. 1982. Neoaplectana carpocapsae: toxin production by axenic insect parasitic nematodes. Nematologica 28:6270.

13. Ehlers, R.-U., U. Wyss, and E. Stackebrandt. 1988. 16S rRNA cataloguing and the phylogenetic position of the genus $\mathrm{Xe}$ norhabdus. Syst. Appl. Microbiol. 10:121-125.

14. Endo, B. Y., and W. R. Nickle. 1991. Ultrastructure of the intestinal epithelium, lumen and associated bacteria in Heterorhabditis bacteriophora. J. Helminthol. Soc. Wash. 58:202212.

15. Farmer, J. J. 1984. Other genera of the family Enterobacteriaceae, p. 506-516. In N. R. Krieg and J. G. Holt (ed.), Bergey's manual of systematic bacteriology, vol. 1. Williams and Wilkins, Baltimore.

16. Farmer, J. J., J. H. Jorgensen, P. A. Grimont, R. J. Akhurst, G. O. Poinar, E. Ageron, G. V. Pierce, J. A. Smith, G. P. Carter, K. L. Wilson, and F. W. Hickman-Brenner. 1989. Xenorhabdus luminescens (DNA hybridization group 5) from human clinical specimens. J. Clin. Microbiol. 27:1594-1602.

17. Götz, P., A. Boman, and N. Boman. 1981. Interaction between insect immunity and an insect pathogenic nematode with symbiotic bacteria. Proc. R. Soc. Lond. B Biol. Sci. 212:333-350.

18. Grimont, P. A., A. G. Steigerwalt, N. E. Boemare, F. W. Hickman-Brenner, C. Deval, F. Grimont, and D. Brenner. 1984. Deoxyribonucleic acid relatedness and phenotypic study of the genus Xenorhabdus. Int. J. Syst. Bacteriol. 34:378-388.

19. Han, R., W. M. Wouts, and L. Li. 1990. Development of Heterorhabditis spp. strains as characteristics of possible Xenorhabdus luminescens subspecies. Rev. Nematol. 13:411415.

20. Hill, E. B., L. G. Wayne, and W. M. Gross. 1972. Purification of mycobacterial deoxyribonucleic acid. J. Bacteriol. 112:10331039.

21. Janse, J. D., and P. H. Smits. 1990. Whole cell fatty acid patterns of Xenorhabdus species. Lett. Appl. Microbiol. 10: 131-135.

22. Lachance, M.-A. 1980. Simple method for determination of deoxyribonucleic acid relatedness by thermal elution in hydroxyapatite microcolumns. Int. J. Syst. Bacteriol. 30:433-436.

23. Maniatis, T., E. F. Fritsch, and J. Sambrook. 1982. Molecular cloning: a laboratory manual. Cold Spring Harbor Laboratory, Cold Spring Harbor, N.Y.

24. Poinar, G. O., and G. M. Thomas. 1966. Significance of Achromobacter nematophilus Poinar \& Thomas (Achromobacteriaceae:Eubacteriales) in the development of the nematode, DD136 (Neoaplectana sp. Steinernematidae). Parasitology 56: 385-390.

25. Poinar, G. O., and G. M. Thomas. 1967. The nature of Achromobacter nematophilus as an insect pathogen. J. Invertebr. Pathol. 9:510-514.

26. Pütz, J., F. Meinert, U. Wyss, R.-U. Ehlers, and E. Stacke- 
brandt. 1990. Development and application of oligonucleotide probes for molecular identification of Xenorhabdus species. Appl. Environ. Microbiol. 56:181-186.

27. Snedecor, G. W., and W. G. Cochran. 1967. Statistical methods, 6th ed. Iowa State University Press, Ames.

28. Suzuki, T., S. Yamanaka, and Y. Nishimura. 1990. Chemotax- onomic study of Xenorhabdus species-cellular fatty acids, ubiquinone and DNA-DNA hybridization. J. Gen. Appl. Microbiol. 36:393-401.

29. Thomas, G. M., and G. O. Poinar. 1979. Xenorhabdus gen. nov., a genus of entomopathogenic bacteria of the family Enterobacteriaceae. Int. J. Syst. Bacteriol. 29:352-360. 